\title{
Theoretical identification of structural heterogeneities of divalent nickel active sites in NiMCM-41 nanoporous catalysts
}

\author{
Mahboobeh Balar $^{1} \cdot$ Zahra Azizi $^{1} \cdot$ Mohammad Ghashghaee $^{2}$
}

Received: 19 September 2016/Accepted: 12 October 2016/Published online: 20 October 2016

(C) The Author(s) 2016. This article is published with open access at Springerlink.com

\begin{abstract}
This paper deals with the theoretical identification of the digrafted $\mathrm{Ni}$ species exchanged into the defect sites of MCM-41 using hybrid density functional theory. The nickel-siloxane clusters included seven $2 \mathrm{~T}-6 \mathrm{~T}$ rings. The 2MR and 5MR structures were found to be the least and most favorable sites to form thermodynamically. The $\mathrm{Ni}-\mathrm{O}$ distances ranged from 1.69 to $1.79 \AA$ with the highest asymmetry found in 5MR. The 4MR and 5MR clusters showed also interesting intertwined nickel configurations. Overall, the QTAIM calculations revealed the transient electrostatic nature of the $\mathrm{Ni}-\mathrm{O}$ bonds.
\end{abstract}

Keywords Nickel · MCM-41 - DFT · Thermodynamics · Cluster modeling $\cdot$ Silica

\section{Introduction}

Nickel ions supported on different silica, silica-alumina, natural clay, and zeolite-type porous materials are wellknown catalysts for the selective dimerization [1-9] and oligomerization [1, 5, 10-19] of olefins in both gas and liquid phases. The application of silica-supported nickel catalysts for the ethylene dimerization dates back to 1980 s [20-22]. Later, the large and well-ordered cavities of the $\mathrm{Ni}$-exchanged MCM-41 proved highly favorable for the oligomerization of olefins [23]. For instance, high

Zahra Azizi

zahra.azizi@kiau.ac.ir; zahraazizi@yahoo.com

1 Department of Chemistry, Karaj Branch, Islamic Azad University, P.O. Box 31485-313, Karaj, Iran

2 Faculty of Petrochemicals, Iran Polymer and Petrochemical Institute, P.O. Box 14975-112, Tehran, Iran productivities of oligomers were obtained over Ni-incorporated MCM-41 catalysts [17] being higher than those reported previously with silica-alumina supports [19]. The strong interactions of $\mathrm{Ni}^{2+}$ cations residing in the mesoporous cavities with the support framework made the reduction of the nickel ions difficult [17]. Further electron spin resonance (ESR) and Fourier transform infrared (FTIR) spectroscopic data [11, 24] served as evidence to support the role of $\mathrm{Ni}^{2+}$ cations as active sites in ethylene dimerization.

The nickel ions incorporated into the ordered mesoporous materials (OMMs) have also been suggested as efficient catalysts for the gas-phase transformation of ethylene to propylene [25-34]. For instance, the performance and durability of Ni/MCM-41 catalysts prepared from a nickel citrate precursor was ranked as auspicious with a promising potential for closing the gap between the propylene demand and supply [35]. Ikeda et al. [36] proposed that layered nickel-silicate species were the main players in the conversion of ethylene on NiMCM-41 catalysts. In a similar study [4], the threefold coordinated $\mathrm{Ni}^{2+}$ ions situated in the 5-membered rings of the phyllosilicate pore walls of NiMCM-41 were taken as the active sites of the reaction.

Computational studies of $\mathrm{Ni}^{2+}$ binding in FER [37], MFI [38, 39], AFI [40], and silica [4, 41] have been reported earlier. Analogous reports have addressed neutral atoms [42, 43]. The present study aims at a systematic theoretical modeling of the locations of $\mathrm{Ni}^{2+}$ species in a model MCM-41 material at the fundamental level. To our knowledge, the most relevant publication to this target is that by Neiman [41] who considered an $\mathrm{O}_{3}(\mathrm{SiO})_{2} \mathrm{Ni}$ structure unit cell with a formal charge of +2 for the nickel ion. The author did not investigate all of the defect sites available for the $\mathrm{Ni}^{2+}$ siting. This work is then the first 


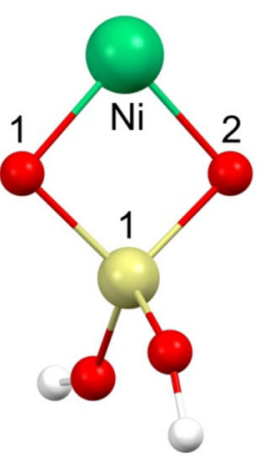

$2 \mathrm{MR}$

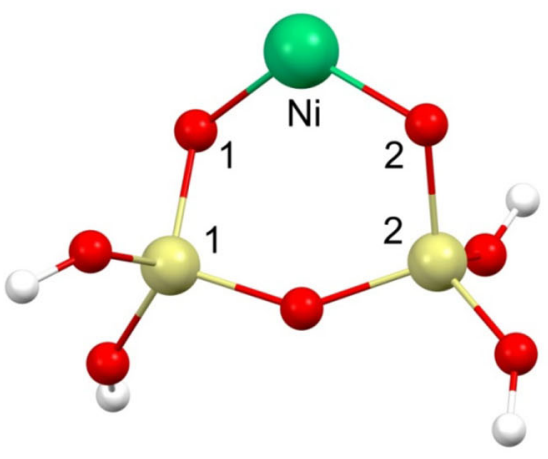

$3 \mathrm{MR}$

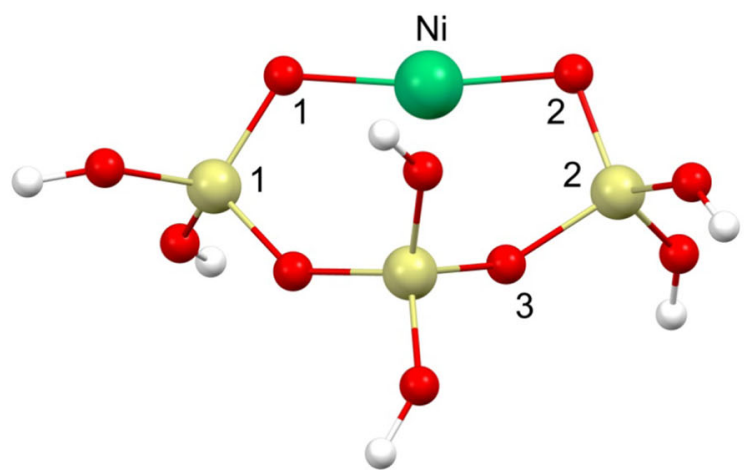

$4 \mathrm{MR}$

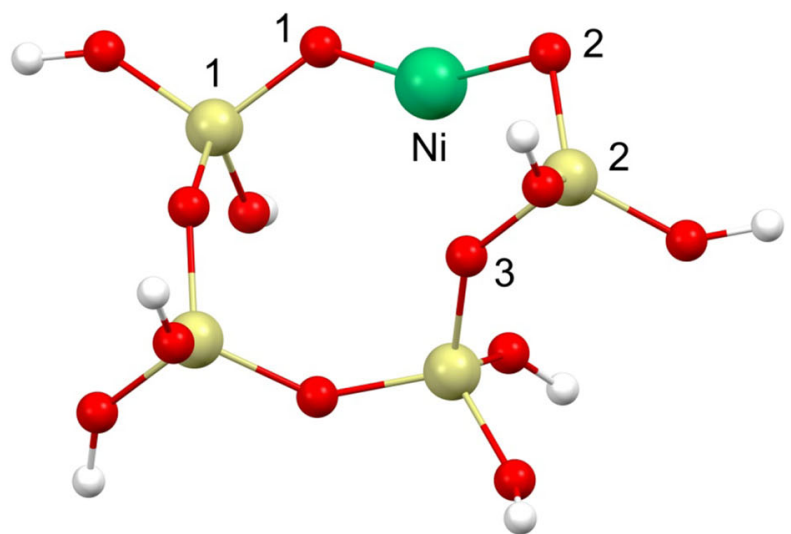

$5 \mathrm{MR}$

Fig. 1 The optimized geometries of the NiMCM-41 clusters where the darker atoms refer to the framework oxygen, the plain bigger balls are silicon atoms and the small white balls are terminal hydrogen atoms. The largest atoms represent nickel

fundamental report on the molecular-level heterogeneities of the NiMCM-41 catalysts.

\section{Computational method}

The cluster model approach was employed to simulate the active sites of a nanoporous NiMCM-41 catalyst through exploring the available defect sites of MCM-41 within an extended unit cell. As a common approach [44, 45], the model nanoclusters were terminated by $\mathrm{H}$ atoms frozen in agreement with the geometries obtained from the crystallographic data [46-51]. The divalent nickel cation and the immediate neighbors including the $\mathrm{O}$ atoms from two defect-site hydroxyls were allowed to relax during the optimizations. As adopted earlier [52], the remaining part of the cluster was held fixed to mimic the mechanical restrictions of the matrix.

As an approximation, the structure of cristobalite is normally taken as a good representative for the amorphous silica materials in terms of type and density of the surface hydroxyl groups [51, 53-56]. Many references [42, 43, 57-60] have then applied this model to ordered silica mesoporous materials such as MCM-41. The optimizations and single-point computations were implemented using hybrid functional M06 [61] and the Def2TZVP basis set [62-64]. Moreover, the natural bond orbital (NBO) population [65] as well as the quantum theory of atoms in molecules (QTAIM) [66-71] analyses were carried out at the same level of theory.

The ion exchange energies $\left(\Delta E_{\mathrm{ex}}\right)$ were calculated for the following reaction:

$[\mathrm{SiO}]-(\mathrm{OH})_{2}+\mathrm{Ni}\left(\mathrm{NO}_{3}\right)_{2} \rightarrow[\mathrm{SiO}]-\mathrm{O}_{2} \mathrm{Ni}+2 \mathrm{HNO}_{3}$

Moreover, the binding energies $\left(\Delta E_{\mathrm{b}}\right)$ for the nickel ions at the defect sites of MCM-41 were assessed for the following reaction:

$[\mathrm{SiO}]-\mathrm{O}_{2} \mathrm{Ni} \rightarrow[\mathrm{SiO}]-\mathrm{O}_{2}^{2-}+\mathrm{Ni}^{2+}$

NWChem 6.5 [72] and Multiwfn 3.3.8 [73] were used for the computations. Finally, the graphical outputs were generated by Mercury 3.3 [74-77]. 


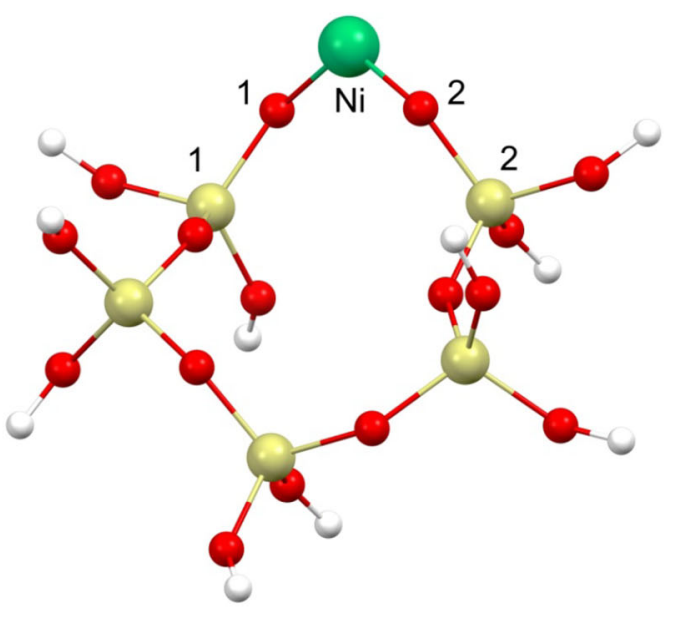

6MR-1

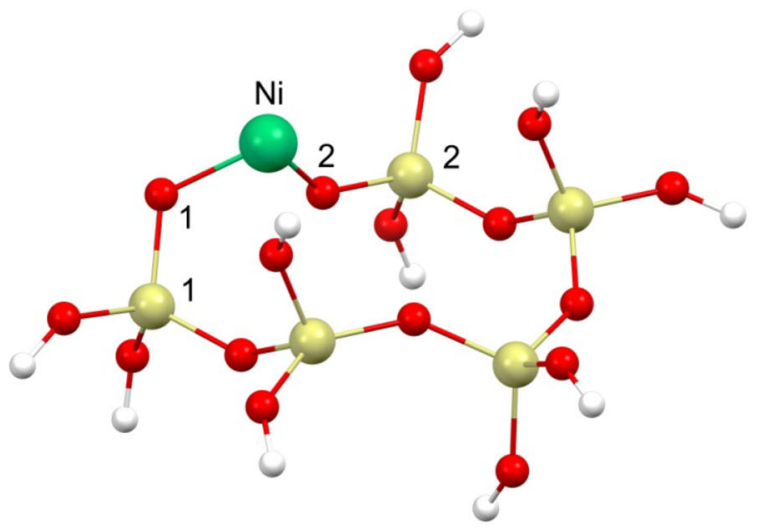

$6 \mathrm{MR}-2$

Fig. 1 continued

\section{Results and discussion}

The viable defect sites of MCM-41 for the binding of the divalent nickel ions were determined from exploring the available pairs of vicinal and close non-vicinal silanol groups. Different NiMCM-41 clusters were considered in terms of the number of T-atoms present in the final rings and the interatomic distances between the next-nearestneighbor $\mathrm{Si}$ atoms with respect to the $\mathrm{Ni}$ cation. The optimized geometries are shown in Fig. 1. As can be seen, different oxide rings can be formed varying from a simple 2T (a digrafted nickel species stabilized with an interaction with two geminal-type $\mathrm{Si}-\mathrm{O}$ groups) to tri, tetra, penta, and hexa membered ones. To our knowledge, this heterogeneity and its consequences are discussed theoretically for the first time. As such, the simplest cluster was a $2 \mathrm{MR}$ ring followed by a $3 \mathrm{MR}$ structure with a nickel cation chemisorbed on two vicinal $\mathrm{OH}$ groups located at the two ends of a siloxane bridge. The other clusters represent relatively more complex types of $\mathrm{Ni}$ binding with proximate non-

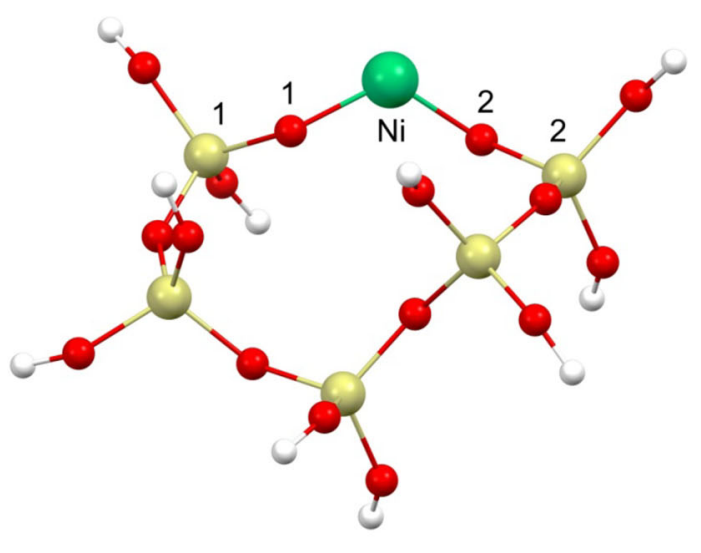

6MR-3 vicinal $\mathrm{OH}$ groups at two defect sites of the surface linked together via two or more consecutive siloxane bridges (Fig. 1). For the comparisons made here, it will be assumed [78] that the dispersion of the $\mathrm{Ni}^{2+}$ species at the defect sites of MCM-41 is controlled by their thermodynamic stability and not by any kinetic phenomenon in the preparation method.

Table 1 reports the NBO charges of the selected atoms of the NiMCM-41 clusters. As can be seen, the partial charge of the $\mathrm{Ni}$ cation ranged from 0.889 e for $2 \mathrm{MR}$ to $1.077 \mathrm{e}$ for $4 \mathrm{MR}$, being almost half the formal charge of +2 for the $\mathrm{Ni}$ ions. Except $2 \mathrm{MR}$ and $3 \mathrm{MR}$, the bridging $\mathrm{O}$ atoms of the $\mathrm{O}_{2} \mathrm{Ni}$ species did not bear identical charges, falling into the range of $-1.157 \mathrm{e}$ to $-1.020 \mathrm{e}$ being almost half the formal charge of -2 for the $\mathrm{O}$ atoms. Although not linearly correlated, there was a general proportional trend between $q(\mathrm{Ni})$ and $-q(\mathrm{O})$. Such an interconnection was not confirmed on the Mulliken atomic charges (see Table 1). Moreover, the average Mulliken charges of $\mathrm{Ni}$ and $\mathrm{O}$ atoms were generally 0.60 and 0.46 times those of the NBO 
Table 1 Calculated charges of selected atoms of NiMCM-41 for different cluster models at M06/Def2-TZVP level of theory

\begin{tabular}{llllll}
\hline Cluster & $\mathrm{Ni}$ & $\mathrm{O}_{1}$ & $\mathrm{O}_{2}$ & $\mathrm{Si}_{1}$ & $\mathrm{Si}_{2}$ \\
\hline \multicolumn{2}{l}{ NBO partial charges } & & & & \\
2MR & 0.889 & -1.021 & -1.020 & 2.353 & - \\
3MR & 0.952 & -1.071 & -1.069 & 2.442 & 2.434 \\
4MR & 1.077 & -1.157 & -1.110 & 2.428 & 2.410 \\
5MR & 1.061 & -1.149 & -1.115 & 2.442 & 2.402 \\
6MR-1 & 0.951 & -1.073 & -1.089 & 2.464 & 2.460 \\
6MR-2 & 1.016 & -1.022 & -1.150 & 2.445 & 2.451 \\
6MR-3 & 0.939 & -1.076 & -1.069 & 2.445 & 2.444 \\
Mulliken atomic charges & & & & \\
2MR & 0.590 & -0.522 & -0.521 & 0.918 & - \\
3MR & 0.589 & -0.535 & -0.537 & 0.855 & 0.864 \\
4MR & 0.566 & -0.486 & -0.492 & 0.782 & 0.822 \\
5MR & 0.565 & -0.492 & -0.500 & 0.770 & 0.812 \\
6MR-1 & 0.603 & -0.505 & -0.509 & 0.758 & 0.755 \\
6MR-2 & 0.582 & -0.467 & -0.437 & 0.770 & 0.764 \\
6 MR-3 & 0.568 & -0.479 & -0.498 & 0.795 & 0.791 \\
\hline
\end{tabular}

Table 2 The Gibbs free energy $(\mathrm{kcal} / \mathrm{mol})$, enthalpy $(\mathrm{kcal} / \mathrm{mol})$, and entropy $(\mathrm{cal} / \mathrm{mol} / \mathrm{K})$ of the exchange reaction and the binding energy ( $\mathrm{kcal} / \mathrm{mol})$ of the digrafted Ni ions in NiMCM-41 at M06/Def2-TZVP level of theory (please see the corresponding reactions in the text)

\begin{tabular}{lllll}
\hline Cluster & $\Delta H_{\text {ex }}$ & $\Delta S_{\text {ex }}$ & $\Delta G_{\text {ex }}$ & $\Delta E_{\mathrm{b}}$ \\
\hline 2MR & 84.90 & 0.04 & 72.72 & 831.5 \\
3MR & 77.78 & 0.04 & 66.47 & 783.4 \\
4MR & 71.35 & 0.03 & 61.72 & 780.6 \\
5MR & 63.01 & 0.03 & 53.99 & 793.8 \\
6MR-1 & 72.52 & 0.04 & 60.51 & 813.4 \\
6MR-2 & 72.54 & 0.04 & 61.67 & 813.3 \\
6MR-3 & 75.60 & 0.05 & 60.22 & 803.6 \\
\hline
\end{tabular}

Table 3 Nickel-oxygen bond length $(\AA)$ and interbond angle (in degree) for different optimized cluster models at M06/Def2-TZVP level of theory

\begin{tabular}{llll}
\hline Cluster & \multicolumn{2}{l}{ Bond lengths } & $\begin{array}{c}\text { Angles } \\
\text { nynn}\end{array}$ \\
\cline { 2 - 3 } & $\mathrm{Ni}-\mathrm{O}_{1}$ & $\mathrm{Ni}-\mathrm{O}_{2}$ & $\mathrm{O}_{1}-\mathrm{Ni}-\mathrm{O}_{2}$ \\
\hline $2 \mathrm{MR}$ & 1.75 & 1.75 & 85.6 \\
$3 \mathrm{MR}$ & 1.74 & 1.75 & 119.4 \\
$4 \mathrm{MR}$ & 1.78 & 1.78 & 168.9 \\
$5 \mathrm{MR}$ & 1.76 & 1.79 & 154.6 \\
$6 \mathrm{MR}-1$ & 1.69 & 1.70 & 118.9 \\
$6 \mathrm{MR}-2$ & 1.71 & 1.72 & 105.2 \\
$6 \mathrm{MR}-3$ & 1.69 & 1.70 & 120.9 \\
\hline
\end{tabular}

Table 4 QTAIM data for different optimized clusters at M06/Def2TZVP level of theory

\begin{tabular}{lllllll}
\hline Cluster & $\mathrm{BCP}$ & $\rho$ & $\lambda_{1}$ & $\lambda_{2}$ & $\lambda_{3}$ & $\nabla^{2} \rho$ \\
\hline 2MR & $\mathrm{Ni}-\mathrm{O}_{1}$ & 0.152 & -0.245 & -0.225 & 1.111 & 0.641 \\
& $\mathrm{Ni}-\mathrm{O}_{2}$ & 0.152 & -0.245 & -0.226 & 1.112 & 0.642 \\
3MR & $\mathrm{Ni}-\mathrm{O}_{1}$ & 0.154 & -0.264 & -0.251 & 1.241 & 0.725 \\
& $\mathrm{Ni}-\mathrm{O}_{2}$ & 0.153 & -0.261 & -0.247 & 1.217 & 0.709 \\
4MR & $\mathrm{Ni}-\mathrm{O}_{1}$ & 0.132 & -0.172 & -0.155 & 1.066 & 0.739 \\
& $\mathrm{Ni}-\mathrm{O}_{2}$ & 0.134 & -0.153 & -0.144 & 1.015 & 0.719 \\
& $\mathrm{Ni}-\mathrm{O}_{3}$ & 0.032 & -0.028 & -0.012 & 0.167 & 0.127 \\
5MR & $\mathrm{Ni}-\mathrm{O}_{1}$ & 0.144 & -0.268 & -0.217 & 1.264 & 0.779 \\
& $\mathrm{Ni}-\mathrm{O}_{2}$ & 0.130 & -0.151 & -0.137 & 0.988 & 0.700 \\
& $\mathrm{Ni}-\mathrm{O}_{3}$ & 0.043 & -0.045 & -0.036 & 0.276 & 0.195 \\
6MR-1 & $\mathrm{Ni}-\mathrm{O}_{1}$ & 0.172 & -0.312 & -0.297 & 1.493 & 0.884 \\
& $\mathrm{Ni}-\mathrm{O}_{2}$ & 0.169 & -0.303 & -0.290 & 1.462 & 0.869 \\
$6 \mathrm{MR}-2$ & $\mathrm{Ni}-\mathrm{O}_{1}$ & 0.165 & -0.277 & -0.276 & 1.347 & 0.794 \\
& $\mathrm{Ni}-\mathrm{O}_{2}$ & 0.156 & -0.251 & -0.233 & 1.306 & 0.822 \\
6MR-3 & $\mathrm{Ni}-\mathrm{O}_{1}$ & 0.172 & -0.316 & -0.299 & 1.512 & 0.897 \\
& $\mathrm{Ni}-\mathrm{O}_{2}$ & 0.172 & -0.313 & -0.296 & 1.490 & 0.881 \\
\hline
\end{tabular}

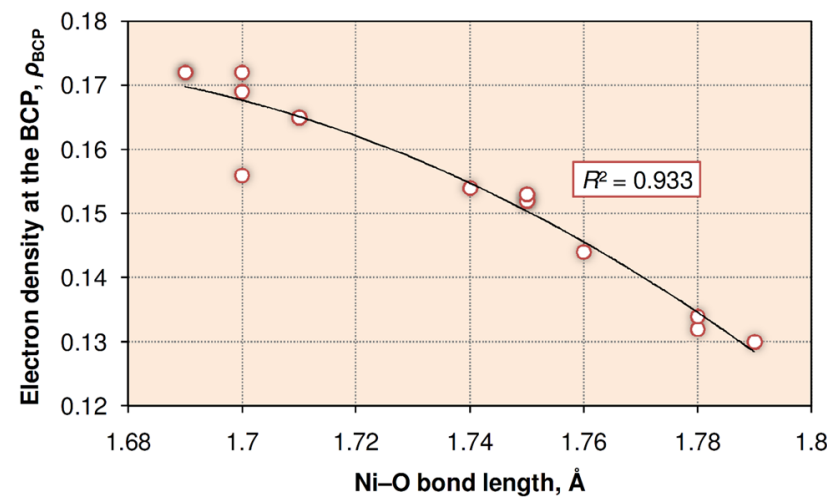

Fig. 2 The correlation found between the topological properties and the $\mathrm{Ni}-\mathrm{O}$ distances in the NiMCM-41 catalysts

Table 5 Calculated HOMO and LUMO and HOMO-LUMO energy gaps $\left(\Delta E_{\text {HOMO-LUMO }}\right)$ for the investigated clusters at M06/Def2TZVP level of theory

\begin{tabular}{llll}
\hline Cluster & $E_{\text {HOMO }}(\mathrm{eV})$ & $E_{\text {LUMO }}(\mathrm{eV})$ & $\Delta E_{\text {HOMO-LUMO }}(\mathrm{eV})$ \\
\hline $2 \mathrm{MR}$ & -7.19 & -3.04 & 4.15 \\
$3 \mathrm{MR}$ & -7.46 & -3.86 & 3.61 \\
$4 \mathrm{MR}$ & -7.30 & -4.29 & 3.01 \\
$5 \mathrm{MR}$ & -7.11 & -3.85 & 3.26 \\
$6 \mathrm{MR}-1$ & -7.11 & -3.32 & 3.78 \\
$6 \mathrm{MR}-2$ & -7.16 & -3.27 & 3.89 \\
$6 \mathrm{MR}-3$ & -7.42 & -3.70 & 3.72 \\
\hline
\end{tabular}


calculations and then even more distant from the nominal charges.

Table 2 contains the enthalpy, entropy, and Gibbs free energy of the exchange reaction for the NiMCM-41clusters and the binding energies of $\mathrm{Ni}$ at the investigated sites following Eqs. (1) and (2), respectively. As evident, the grafting reaction considered here is non-spontaneous at $298 \mathrm{~K}$ and atmospheric pressure on all of the clusters, connoting the necessity for devising more severe (e.g., hydrothermal) preparation conditions to overcome the exchange non-spontaneity. In any event, the thermodynamic favorability for grafting of the $\mathrm{Ni}^{2+}$ cations onto the available defect sites of MCM-41 followed the sequence of $2 \mathrm{MR}<3 \mathrm{MR}<4 \mathrm{MR}<6 \mathrm{MR}-3<6 \mathrm{MR}-1<6 \mathrm{MR}$ -

$2<5 \mathrm{MR}(53.99-72.72 \mathrm{kcal} / \mathrm{mol})$. This is in accordance with the previous ideas on the favorability of 5MR structures mentioned previously. Moreover, the enthalpy of the exchange reaction followed the order of $5 \mathrm{MR}<4 \mathrm{MR}<6 \mathrm{MR}-1<6 \mathrm{MR}-2<6 \mathrm{MR}-$

$3<3 \mathrm{MR}<2 \mathrm{MR}, \quad$ all being endothermic (63.09-84.10 kcal/mol). However, the binding energy for this reaction varied in the order of $4 \mathrm{MR}<3 \mathrm{MR}<5 \mathrm{MR}<6 \mathrm{MR}-3<6 \mathrm{MR}-2<6 \mathrm{MR}-$

$1<2 \mathrm{MR}(780.6-831.5 \mathrm{kcal} / \mathrm{mol})$. As a result, the $2 \mathrm{MR}$ site is more demanding to form despite its largest binding energy.

In Table 3, the nickel-oxygen bond lengths and the interbond angles of $\mathrm{Ni}$ have been listed for comparison. The bridging $(\mathrm{Ni}-\mathrm{O})$ bond lengths fell into the range of 1.69-1.79 $\AA$ with the highest asymmetry [a difference of $0.03 \AA$ between $r(\mathrm{Ni}-\mathrm{O} 1)$ and $r(\mathrm{Ni}-\mathrm{O} 2)]$ found in the case of $5 \mathrm{MR}$. The $\mathrm{O}-\mathrm{Ni}-\mathrm{O}$ angles changed over a markedly wider range here with the minimum angle $\left(85.6^{\circ}\right)$ on $2 \mathrm{MR}$ and the largest one $\left(168.9^{\circ}\right)$ on $4 \mathrm{MR}$. The data reported here indicated that neither the $\mathrm{Ni}-\mathrm{O}$ distances nor the $\mathrm{O} 1-$ $\mathrm{Ni}-\mathrm{O} 2$ angles correlated with the size of the siloxane rings as analogously expressed in our previous study of $\mathrm{Cr}-$ silicalite-2 [79].

The characterizing features [71, 80, 81] of QTAIM were employed to determine whether the nickel-oxide solid interactions were of shared or closed-shell nature. The calculated topological properties are shown in Table 4 . The tabulated data represent moderate electron densities $\left(\rho_{\mathrm{BCP}}\right)$. Moreover, positive $\nabla^{2} \rho_{\mathrm{BCP}}$ values were obtained as anticipated from a common character of metal-oxygen interactions [80]. The interactions of nickel with the siloxane rings of MCM-41 were all found to be rather polar than purely covalent. More interestingly, however, the 4MR and 5MR structures revealed third Ni-O interactions of electrostatic nature that made the nickel ion interlocked three-coordinated in the plane of the ring. Potential correlations between the properties of the NiMCM-41 active sites were probed. Figure 2 shows an obvious correlation between $r(\mathrm{Ni}-\mathrm{O})$ and $\rho_{\mathrm{BCP}}$ which was also observed in our previous works on MEL structure [79, 82]. No further correlation with an acceptably high coefficient of determination was found between any other two parameters.

The energy levels of electrons and their gaps provide useful data for implications on the reactivity of the active sites [79, 82, 83] according to the frontier molecular orbital (FMO) theory [84]. Table 5 reports the HOMO and LUMO levels and HOMO-LUMO energy gaps for the optimized clusters shown in Fig. 1. The HOMO-LUMO energy gaps increased in the order of $4 \mathrm{MR}<5 \mathrm{MR}<3 \mathrm{MR}<6 \mathrm{MR}$ $3<6 \mathrm{MR}-1<6 \mathrm{MR}-2<2 \mathrm{MR}$ ranging from 3.01 to $4.15 \mathrm{eV}$. Considering the chemical hardness as $\eta=\left(E_{\mathrm{LUMO}}-E_{\mathrm{HOMO}}\right) / 2$ [85-89], one can state that the chemical hardness of the digrafted nickel ion was maximized at 2MR and minimized at 4MR and 5MR sites.

\section{Conclusion}

This paper investigated the diversity of the cluster models of NiMCM-41 in a systematic computational framework. Total of seven active sites (2T-6T rings) were found at the defect sites of an MCM-41 silica model. The NBO partial charge of the nickel cation was less positive on $2 \mathrm{MR}$ and largest on 4MR. The thermodynamic favorability of the NiMCM-41 clusters followed the order of $2 \mathrm{MR}<3 \mathrm{MR}<4 \mathrm{MR}<6 \mathrm{MR}-3<6 \mathrm{MR}-1<6 \mathrm{MR}-$

$2<5 \mathrm{MR}$. The optimized structures indicated the $\mathrm{Ni}-\mathrm{O}$ distances in the range of 1.69-1.79 $\AA$ with the highest asymmetry observed in 5MR. The highest reactivity was observed in the case of the digrafted nickel ions at $4 \mathrm{MR}$ and 5MR sites and the lowest one at $2 \mathrm{MR}$. The $4 \mathrm{MR}$ and 5MR clusters showed also some intertwining features for nickel hosting. The QTAIM calculations revealed intermediate polar Ni-O bonds. Moreover, the electron densities at the BCP correlated with the $\mathrm{Ni}-\mathrm{O}$ distances.

Open Access This article is distributed under the terms of the Creative Commons Attribution 4.0 International License (http://crea tivecommons.org/licenses/by/4.0/), which permits unrestricted use, distribution, and reproduction in any medium, provided you give appropriate credit to the original author(s) and the source, provide a link to the Creative Commons license, and indicate if changes were made.

\section{References}

1. Andrei, R.D., Popa, M.I., Fajula, F., Hulea, V.: Heterogeneous oligomerization of ethylene over highly active and stable $\mathrm{Ni}$ AlSBA-15 mesoporous catalysts. J. Catal. 323, 76-84 (2015)

2. Andrei, R.D., Mureseanu, M., Popa, M.I., Cammarano, C., Fajula, F., Hulea, V.: Ni-exchanged AlSBA-15 mesoporous materials as outstanding catalysts for ethylene oligomerization. Eur. Phys. J. Special Topics 224(9), 1831-1841 (2015) 
3. Zhang, H., Li, X., Zhang, Y., Lin, S., Li, G., Chen, L., Fang, Y., Xin, H., Li, X.: Ethylene oligomerization over heterogeneous catalysts. Energy Environ. Focus 3(3), 246-256 (2014)

4. Tanaka, M., Itadani, A., Kuroda, Y., Iwamoto, M.: Effect of pore size and nickel content of Ni-MCM-41 on catalytic activity for ethene dimerization and local structures of nickel ions. J. Phys. Chem. C 116(9), 5664-5672 (2012)

5. Iwamoto, M.: One step formation of propene from ethene or ethanol through metathesis on nickel ion-loaded silica. Molecules 16(9), 7844-7863 (2011)

6. Choo, H., Kevan, L.: Catalytic study of ethylene dimerization on Ni(II)-exchanged clinoptilolite. J. Phys. Chem. B 105(27), 6353-6360 (2001)

7. Nkosi, B., Ng, F.T.T., Rempel, G.L.: The oligomerization of butenes with partially alkali exchanged $\mathrm{NiNaY}$ zeolite catalysts. Appl. Catal. A-Gen. 158(1), 225-241 (1997)

8. Sohn, J.R., Park, J.H.: Characterization of dealuminated NiY zeolite and effect of dealumination on catalytic activity for ethylene dimerization. Appl. Catal. A-Gen. 218(1-2), 229-234 (2001)

9. Ng, F.T.T., Creaser, D.C.: Ethylene dimerization over modified nickel exchanged Y-zeolite. Appl. Catal. A-Gen. 119(2), 327-339 (1994)

10. Moussa, S., Arribas, M.A., Concepción, P., Martínez, A.: Heterogeneous oligomerization of ethylene to liquids on bifunctional Ni-based catalysts: the influence of support properties on nickel speciation and catalytic performance. Catal. Today (2016). doi:10.1016/j.cattod.2015.11.032

11. Martínez, A., Arribas, M.A., Concepción, P., Moussa, S.: New bifunctional $\mathrm{Ni}-\mathrm{H}$-Beta catalysts for the heterogeneous oligomerization of ethylene. Appl. Catal. A-Gen. 467, 509-518 (2013)

12. Lallemand, M., Finiels, A., Fajula, F., Hulea, V.: Continuous stirred tank reactor for ethylene oligomerization catalyzed by NiMCM-41. Chem. Eng. J. 172(2), 1078-1082 (2011)

13. Brückner, A., Bentrup, U., Zanthoff, H., Maschmeyer, D.: The role of different $\mathrm{Ni}$ sites in supported nickel catalysts for butene dimerization under industry-like conditions. J. Catal. 266(1), 120-128 (2009)

14. Lallemand, M., Finiels, A., Fajula, F., Hulea, V.: Catalytic oligomerization of ethylene over Ni-containing dealuminated $\mathrm{Y}$ zeolites. Appl. Catal. A-Gen. 301(2), 196-201 (2006)

15. Hulea, V., Lallemand, M., Finiels, A., Fajula, F.: Catalytic oligomerization of ethylene over Ni-containing MCM-22, MCM41 and USY. In: J. Čejka, N.Ž., Nachtigall, P. (eds.) Studies in Surface Science and Catalysis, Part B, vol. 158. pp. 1621-1628. Elsevier, Amsterdam (2005)

16. Lin, S., Shi, L., Zhang, H., Zhang, N., Yi, X., Zheng, A., Li, X.: Tuning the pore structure of plug-containing Al-SBA-15 by posttreatment and its selectivity for $\mathrm{C}_{16}$ olefin in ethylene oligomerization. Microporus and Mesoporus Mat. 184, 151-161 (2014)

17. Hulea, V., Fajula, F.: Ni-exchanged AlMCM-41-an efficient bifunctional catalyst for ethylene oligomerization. J. Catal. 225(1), 213-222 (2004)

18. Nicolaides, C.P., Scurrell, M.S., Semano, P.M.: Nickel silicaalumina catalysts for ethene oligomerization-control of the selectivity to 1-alkene products. Appl. Catal. A-Gen. 245(1), 43-53 (2003)

19. Heydenrych, M.D., Nicolaides, C.P., Scurrell, M.S.: Oligomerization of ethene in a slurry reactor using a nickel(II)-exchanged silica-alumina catalyst. J. Catal. 197(1), 49-57 (2001)

20. Kimura, K., Hideo, A.-I., Ozaki, A.: Tracer study of ethylene dimerization over nickel oxide-silica catalyst. J. Catal. 18(3), 271-280 (1970)

21. Sohn, J.R., Ozaki, A.: Structure of $\mathrm{NiO}-\mathrm{SiO}_{2}$ catalyst for ethylene dimerization as observed by infrared absorption. J. Catal. 59(2), 303-310 (1979)
22. Sohn, J.R., Ozaki, A.: Acidity of nickel silicate and its bearing on the catalytic activity for ethylene dimerization and butene isomerization. J. Catal. 61(1), 29-38 (1980)

23. Finiels, A., Fajula, F., Hulea, V.: Nickel-based solid catalysts for ethylene oligomerization-a review. Catal. Sci. Technol. 4(8), 2412-2426 (2014)

24. Martínez, A., Arribas, M.A., Moussa, S.: Development of bifunctional Ni-based catalysts for the heterogeneous oligomerization of ethylene to liquids. In: Kanellopoulos, N. (ed.) SmallScale Gas to Liquid Fuel Synthesis. pp. 377-400. CRC Press, Boca Raton (2015)

25. Frey, A.S., Hinrichsen, O.: Comparison of differently synthesized $\mathrm{Ni}(\mathrm{Al}) \mathrm{MCM}-48$ catalysts in the ethene to propene reaction. Microporus and Mesoporus Mat. 164, 164-171 (2012)

26. Alvarado Perea, L., Wolff, T., Veit, P., Hilfert, L., Edelmann, F.T., Hamel, C., Seidel-Morgenstern, A.: Alumino-mesostructured $\mathrm{Ni}$ catalysts for the direct conversion of ethene to propene. J. Catal. 305, 154-168 (2013)

27. Alvarado Perea, L., Wolff, T., Hamel, C., Seidel-Morgenstern, A.: Direct conversion of ethene to propene on Ni/AlMCM-41study of the reaction mechanism. In: Jahrestreffen Deutscher Katalytiker, Weimar, Germany (2014)

28. Alvarado Perea, L.: Direct conversion of ethene to propene on Ni-alumino-mesostructured catalysts: synthesis, characterization and catalytic testing. $\mathrm{PhD}$ dissertation, Otto-von-Guericke Universität (2014)

29. Iwamoto, M., Kosugi, Y.: Highly selective conversion of ethene to propene and butenes on nickel ion-loaded mesoporous silica catalysts. J. Phys. Chem. C 111(1), 13-15 (2007)

30. Iwamoto, M.: One step formation of propene from ethene or ethanol through metathesis on nickel ion-loaded silica. Molecules 16, 7844-7863 (2011)

31. Taoufik, M., Le Roux, E., Thivolle-Cazat, J., Basset, J.-M.: Direct transformation of ethylene into propylene catalyzed by a tungsten hydride supported on alumina: trifunctional single-site catalysis. Angew. Chem. 119, 7340-7343 (2007)

32. Taoufik, M., Le Roux, E., Thivolle-Cazat, J., Basset, J.-M.: Direct transformation of ethylene into propylene catalyzed by a tungsten hydride supported on alumina: trifunctional single-site catalysis. Angew. Chem. Int. Ed. 46, 7202-7205 (2007)

33. Iwamoto, M.: Conversion of ethene to propene on nickel ionloaded mesoporous silica prepared by the template ion exchange method. Catal. Surv. Asia 12(1), 28-37 (2008)

34. Lehmann, T., Wolff, T., Zahn, V.M., Veit, P., Hamel, C., SeidelMorgenstern, A.: Preparation of Ni-MCM-41 by equilibrium adsorption-Catalytic evaluation for the direct conversion of ethene to propene. Catal. Commun. 12(5), 368-374 (2011)

35. Zahn, V.M., Wolff, T., Lehmann, T., Hamel, C., Seidel-Morgenstern, A.: Direct synthesis of propene using supported bifunctional nickel catalysts: preparation and potential. In: ISCRE 21-21st International Symposium on Chemical Reaction Engineering (2010)

36. Ikeda, K., Kawamura, Y., Yamamoto, T., Iwamoto, M.: Effectiveness of the template-ion exchange method for appearance of catalytic activity of $\mathrm{Ni}-\mathrm{MCM}-41$ for the ethene to propene reaction. Catal. Commun. 9(1), 106-110 (2008)

37. Šponer, J.E., Sobalík, Z., Leszczynski, J., Wichterlová, B.: Effect of metal coordination on the charge distribution over the cation binding sites of zeolites. A combined experimental and theoretical study. J. Phys. Chem. B 105(35), 8285-8290 (2001)

38. Rice, M.J., Chakraborty, A.K., Bell, A.T.: Site availability and competitive siting of divalent metal cations in ZSM-5. J. Catal. 194(2), 278-285 (2000)

39. Rice, M.J., Chakraborty, A.K., Bell, A.T.: Theoretical studies of the coordination and stability of divalent cations in ZSM-5. J. Phys. Chem. B 104(43), 9987-9992 (2000) 
40. Brogaard, R.Y., Olsbye, U.: Ethene oligomerization in Ni-containing zeolites: theoretical discrimination of reaction mechanisms. ACS Catal. 6(2), 1205-1214 (2016)

41. Neiman, M.L.: Interaction of cobalt and nickel with the hydroxylated silanol silica surface: a theoretical study. MSc thesis, Lehigh University (2002)

42. Ma, Q., Klier, K., Cheng, H., Mitchell, J.W., Hayes, K.S.: Interaction between catalyst and support. 1. Low coverage of Co and $\mathrm{Ni}$ at the silica surface. J. Phys. Chem. B 104(45), 10618-10626 (2000)

43. Ma, Q., Klier, K., Cheng, H., Mitchell, J.W., Hayes, K.S.: Interaction between catalyst and support. 3. Metal agglomeration on the silica surface. J. Phys. Chem. B 105(38), 9230-9238 (2001)

44. Pietrzyk, P.: Spectroscopy and computations of supported metal adducts. 1. DFT study of CO and NO adsorption and coadsorption on $\mathrm{Cu} / \mathrm{SiO}_{2}$. J. Phys. Chem. B 109(20), 10291-10303 (2005)

45. Ferullo, R.M., Garda, G.R., Belelli, P.G., Branda, M.M., Castellani, N.J.: Deposition of small $\mathrm{Cu}, \mathrm{Ag}$ and $\mathrm{Au}$ particles on reduced SiO2. J. Mol. Struct. 769(1-3), 217-223 (2006)

46. Downs, R.T., Palmer, D.C.: The pressure behavior of $\alpha$ cristobalite. Am. Mineral. 79(1-2), 9-14 (1994)

47. Wright, A.F., Leadbetter, A.J.: The structures of the $\beta$-cristobalite phases of $\mathrm{SiO}_{2}$ and $\mathrm{AlPO}_{4}$. Philos. Mag. 31(6), 1391-1401 (1975)

48. Hatch, D.M., Ghose, S.: The $\alpha-\beta$ phase transition in cristobalite, $\mathrm{SiO}_{2}$. Phys. Chem. Miner. 17(6), 554-562 (1991)

49. Leadbetter, A.J., Smith, T.W., Wright, A.F.: Structure of high cristobalite. Nature 244, 125-126 (1973)

50. Peacor, D.R.: High-temperature single-crystal study of the cristobalite inversion. zkri 138(1-4), 274-298 (1973)

51. Pophal, C., Fuess, H.: Investigation of the medium range order of polyhedra forming the walls of MCM-41-An X-ray diffraction study. Microporus and Mesoporus Mat. 33(1-3), 241-247 (1999)

52. Lopez, N., Illas, F., Pacchioni, G.: Adsorption of $\mathrm{Cu}, \mathrm{Pd}$, and $\mathrm{Cs}$ atoms on regular and defect sites of the $\mathrm{SiO}_{2}$ surface. J. Am. Chem. Soc. 121(4), 813-821 (1999)

53. Chuang, I.S., Maciel, G.E.: A detailed model of local structure and silanol hydrogen bonding of silica gel surfaces. J. Phys. Chem. B 101(16), 3052-3064 (1997)

54. Maciel, G.E.: Probing hydrogen bonding and the local environment of silanols on silica surfaces via nuclear spin cross polarization dynamics. J. Am. Chem. Soc. 118(2), 401-406 (1996)

55. Chuang, I.S., Kinney, D.R., Bronnimann, C.E., Zeigler, R.C., Maciel, G.E.: Effects of proton-proton spin exchange in the silicon-29 CP-MAS NMR spectra of the silica surface. J. Phys. Chem. 96(10), 4027-4034 (1992)

56. Sindorf, D.W., Maciel, G.E.: Silicon-29 NMR study of dehydrated/rehydrated silica gel using cross polarization and magicangle spinning. J. Am. Chem. Soc. 105(6), 1487-1493 (1983)

57. Lillehaug, S.: A theoretical study of Cr/oxide catalysts for dehydrogenation of short alkanes. PhD dissertation, University of Bergen (2006)

58. Handzlik, J., Kurleto, K.: Assessment of density functional methods for thermochemistry of chromium oxo compounds and their application in a study of chromia-silica system. Chem. Phys. Lett. 561-562, 87-91 (2013)

59. Lillehaug, S., Jensen, V.R., Børve, K.J.: Catalytic dehydrogenation of ethane over mononuclear Cr(III)-silica surface sites. Part 2: $\mathrm{C}-\mathrm{H}$ activation by oxidative addition. J. Phys. Org. Chem. 19, 25-33 (2006)

60. Chempath, S., Zhang, Y., Bell, A.T.: DFT studies of the structure and vibrational spectra of isolated molybdena species supported on silica. J. Phys. Chem. C 111(3), 1291-1298 (2006)

61. Zhao, Y., Truhlar, D.: The M06 suite of density functionals for main group thermochemistry, thermochemical kinetics, noncovalent interactions, excited states, and transition elements: two new functionals and systematic testing of four M06-class functionals and 12 other functionals. Theor. Chem. Account 120(1-3), 215-241 (2008)

62. Weigend, F.: Accurate Coulomb-fitting basis sets for $\mathrm{H}$ to $\mathrm{Rn}$. Phys. Chem. Chem. Phys. 8(9), 1057-1065 (2006)

63. Weigend, F., Ahlrichs, R.: Balanced basis sets of split valence, triple zeta valence and quadruple zeta valence quality for $\mathrm{H}$ to Rn: design and assessment of accuracy. Phys. Chem. Chem. Phys. 7(18), 3297-3305 (2005)

64. Feller, D.: The role of databases in support of computational chemistry calculations. J. Comput. Chem. 17(13), 1571-1586 (1996)

65. Glendening, E., Badenhoop, J., Reed, A., Carpenter, J., Weinhold, F.: NBO 3.1. Theoretical Chemistry Institute, University of Wisconsin, Madison (1996)

66. Rodríguez, J.I., Bader, R.F.W., Ayers, P.W., Michel, C., Götz, A.W., Bo, C.: A high performance grid-based algorithm for computing QTAIM properties. Chem. Phys. Lett. 472(1-3), 149-152 (2009)

67. Bader, R.F.W.: A quantum theory of molecular structure and its applications. Chem. Rev. 91(5), 893-928 (1991)

68. Bader, R.F.W.: The quantum mechanical basis of conceptual chemistry. Monatsh. Chem. 136(6), 819-854 (2005)

69. Bader, R.F.W.: Molecular fragments or chemical bonds. Accounts Chem. Res. 8(1), 34-40 (1975)

70. Bader, R.F.W.: Atoms in Molecules: A Quantum Theory, vol. 22. International series of monographs on chemistry. Oxford University Press, USA (1994)

71. Matta, C.F., Boyd, R.J.: The quantum theory of atoms in molecules: from solid state to DNA and drug design. Wiley, New York (2007)

72. Valiev, M., Bylaska, E.J., Govind, N., Kowalski, K., Straatsma, T.P., Van Dam, H.J.J., Wang, D., Nieplocha, J., Apra, E., Windus, T.L., de Jong, W.A.: NWChem: a comprehensive and scalable open-source solution for large scale molecular simulations. Comput. Phys. Commun. 181(9), 1477-1489 (2010)

73. Lu, T., Chen, F.: Multiwfn: a multifunctional wavefunction analyzer. J. Comput. Chem. 33(5), 580-592 (2012)

74. Bruno, I.J., Cole, J.C., Edgington, P.R., Kessler, M., Macrae, C.F., McCabe, P., Pearson, J., Taylor, R.: New software for searching the Cambridge structural database and visualizing crystal structures. Acta Crystallogr. B 58(3 Part 1), 389-397 (2002)

75. Macrae, C.F., Bruno, I.J., Chisholm, J.A., Edgington, P.R., McCabe, P., Pidcock, E., Rodriguez-Monge, L., Taylor, R., van de Streek, J., Wood, P.A.: Mercury CSD 2.0-new features for the visualization and investigation of crystal structures. J. Appl. Crystallogr. 41(2), 466-470 (2008)

76. Macrae, C.F., Edgington, P.R., McCabe, P., Pidcock, E., Shields, G.P., Taylor, R., Towler, M., van de Streek, J.: Mercury: visualization and analysis of crystal structures. J. Appl. Crystallogr. 39(3), 453-457 (2006)

77. Taylor, R., Macrae, C.F.: Rules governing the crystal packing of mono- and dialcohols. Acta Crystallogr. B 57(6), 815-827 (2001)

78. Handzlik, J., Grybos, R., Tielens, F.: Structure of monomeric chromium(VI) oxide species supported on silica: periodic and cluster DFT studies. J. Phys. Chem. C 117(16), 8138-8149 (2013)

79. Ghambarian, M., Azizi, Z., Ghashghaee, M.: Diversity of monomeric dioxo chromium species in $\mathrm{Cr} /$ silicalite-2 catalysts: a hybrid density functional study. Comp. Mater. Sci. 118, 147-154 (2016)

80. Sierraalta, A., Añez, R., Brussin, M.-R.: Theoretical study of $\mathrm{NO}_{2}$ adsorption on a transition-metal zeolite model. J. Catal. 205(1), 107-114 (2002)

81. Gatti, C.: Chemical bonding in crystals: new directions. zkri 220, 399-457 (2005) 
82. Ghashghaee, M., Ghambarian, M., Azizi, Z.: Characterization of extraframework $\mathrm{Zn}^{2+}$ cationic sites in silicalite-2: a computational study. Struct. Chem. 27(2), 467-475 (2016)

83. Ghambarian, M., Ghashghaee, M., Azizi, Z., Balar, M.: Effect of cluster size in computational modeling of $\mathrm{Cu}^{+} / \mathrm{ZSM}-11$ catalysts. In: 3rd International Congress of Chemistry and Chemical Engineering, pp. 292-299 (2016)

84. Fukui, K., Yonezawa, T., Shingu, H.: A molecular orbital theory of reactivity in aromatic hydrocarbons. J. Chem. Phys. 20(4), 722-725 (1952)

85. Parthasarathi, R., Subramanian, V., Chattaraj, P.K.: Effect of electric field on the global and local reactivity indices. Chem. Phys. Lett. 382(1-2), 48-56 (2003)
86. Parr, R.G., Szentpály, Lv, Liu, S.: Electrophilicity Index. J. Am. Chem. Soc. 121(9), 1922-1924 (1999)

87. Parr, R.G., Pearson, R.G.: Absolute hardness: companion parameter to absolute electronegativity. J. Am. Chem. Soc. 105(26), 7512-7516 (1983)

88. Datta, D.: On Pearson's HSAB Principle. Inorg. Chem. 31(13), 2797-2800 (1992)

89. Parr, R.G., Weitao, Y.: Density-functional theory of atoms and molecules. International Series of Monographs on Chemistry. Oxford University Press, New York (1989) 